\title{
THE RACIAL ECOLOGY OF LEAD POISONING
}

\section{Toxic Inequality in Chicago Neighborhoods, 1995-2013}

\author{
Robert J. Sampson \\ Department of Sociology, Harvard University
}

\author{
Alix S. Winter \\ Department of Sociology, Harvard University
}

\begin{abstract}
This paper examines the racial ecology of lead exposure as a form of environmental inequity, one with both historical and contemporary significance. Drawing on comprehensive data from over one million blood tests administered to Chicago children from 1995-2013 and matched to over 2300 geographic block groups, we address two major questions: (1) What is the nature of the relationship between neighborhood-level racial composition and variability in children's elevated lead prevalence levels? And (2) what is the nature of the relationship between neighborhood-level racial composition and rates of change in children's prevalence levels over time within neighborhoods? We further assess an array of structural explanations for observed racial disparities, including socioeconomic status, type and age of housing, proximity to freeways and smelting plants, and systematic observations of housing decay and neighborhood disorder. Overall, our theoretical framework posits lead toxicity as a major environmental pathway through which racial segregation has contributed to the legacy of Black disadvantage in the United States. Our findings support this hypothesis and show alarming racial disparities in toxic exposure, even after accounting for possible structural explanations. At the same time, however, our longitudinal results show the power of public health policies to reduce racial inequities.
\end{abstract}

Keywords: Lead Poisoning, Inequality, Segregation, Neighborhoods, Chicago, Public Health

\section{INTRODUCTION}

The link between racial segregation and multiple social adversities is a central feature of the American landscape. A well-documented fact is the nexus of concentrated poverty and the spatial isolation of African Americans (Massey and Denton, 1993; Wilson [1987] 2012), a connection that spans decades and remains stubbornly persistent. Nationwide, for example, close to a third of Black children born between 1985 and 2000 
were raised in high-poverty neighborhoods compared with just $1 \%$ of White children (Sharkey 2013). The racial stratification of America's urban neighborhoods is not just about group differences in income-affluent Blacks typically live in poorer neighborhoods than the average lower-income White resident (Perkins and Sampson, 2015). Black neighborhoods also disproportionately experience higher rates of unemployment, single-parent families, teenage childbearing, violence, incarceration, and high school dropout (Sampson 2012).

Less studied but equally important is the neighborhood divide by race in the fundamentals of physical health and well-being. As with compounded social deprivation, indicators of compromised health, such as infant mortality, low birth weight, heart disease, and cancer, tend to be the highest in racially-segregated, poor neighborhoods (Krieger 2014; Williams and Collins, 2001). The recognition that Black neighborhoods endure a disproportionate share of physical health burdens is not new. Over a hundred years ago, W. E. B. Du Bois demonstrated that Blacks in Philadelphia dwelled "in the most unhealthful parts of the city" (1899, p. 148). Near the middle of the twentieth century, St. Clair Drake and Horace Cayton mapped "disease and death" (1945, p. 205) in Black Metropolis, revealing higher rates of tuberculosis and infant mortality in Chicago's Black communities. Although health conditions have generally improved since these classic works, contemporary research largely confirms that Black neighborhoods still rank higher on multiple indicators of poor physical health (Acevedo-Garcia and Lochner, 2003).

Yet as the crisis in Flint Michigan revealed (Goodnough 2016), there is a major health scourge that has not been subjected to the same analytic scrutiny at the neighborhood level as other health indicators-lead poisoning. Unlike longstanding health concerns, it was not until relatively recently that a sizable body of research built up and converged in concluding that lead is a major neurotoxin that impairs cognitive, physical, and behavioral functioning, even at relatively low levels (Rogan and Ware, 2003). As the National Research Council argued just over twenty years ago: "Science and society have been remarkably slow to recognize and respond to the full range of harm associated with lead exposure" (1993, p.1). So too, we argue, have science and society been slow to recognize the racial ecology of lead poisoning as a major form of health inequality. In particular, although Black children have been shown to be at higher risk of lead exposure than White or Hispanic children (Lanphear et al., 1996), surprisingly little research has systematically examined the magnitude of lead poisoning in minority communities. The structural sources of racial disparities in lead poisoning at the neighborhood level are also sparsely researched. And just as important, there is little, if any, research that explores whether the large rates of decline in lead exposure since the 1990s have been evenly experienced in Black, Hispanic, and White communities.

Our paper fills this void by exploring the racial stratification of lead exposure as an underappreciated source of ecological inequity, one with both historical and contemporary significance. Drawing on comprehensive data from over one million blood tests administered to Chicago children compiled over the years 1995-2013 and matched to over 2300 geographic block groups, we address two major questions: (1) What is the nature of the relationship between neighborhood-level racial composition and variability in children's elevated lead prevalence levels? And (2) what is the nature of the relationship between neighborhood-level racial composition and rates of change of children's prevalence levels within neighborhoods? We enlist a rich set of structural covariates that may explain observed racial disparities, including socioeconomic status, type and age of housing structures, proximity to freeways and smelting plants, and videotaped observations of housing decay and neighborhood disorder. 
Overall, our theoretical framework posits lead toxicity as an environmental pathway through which racial segregation has contributed to the legacy of racial inequality in the United States. Our findings support this claim and show alarming racial disparities in toxic exposure. But at the same time, our longitudinal results show the power of public health policies to reduce racial inequities.

\section{THE ECOLOGY OF TOXIC INEQUALITY}

The science of lead poisoning has evolved sharply in recent decades. Although lead was recognized to have potentially harmful effects since the beginning of the twentieth century, research pinpointing its consequences for children's psychological, behavioral, and cognitive development coalesced in the 1970s (Needleman et al., 1979). Since then, evidence of a direct relationship between early childhood lead exposure and developmental outcomes has accumulated at a rapid pace, especially with respect to cognitive functioning (Bellinger et al., 1991) and antisocial behavior (Needleman et al., 1996). The threshold at which lead exposure is considered to be safe has also been continually lowered. By 1991, the Centers for Disease Control and Prevention (CDC) recommended monitoring for children with blood lead levels (BLL) $\geq 10 \mu \mathrm{g} / \mathrm{dL}$. However, researchers subsequently showed negative consequences among children with even lower levels of exposure (Canfield et al., 2003). Bruce Lanphear and colleagues summarize the shift in thinking: "The impact of low-level environmental lead exposure on the health of the public is substantial" (2005, p. 899). In 2012, the CDC went further to declare that there is no safe level of lead exposure, changing its recommendation to BLL $\geq 5 \mu \mathrm{g} / \mathrm{dL}$ as the "reference level" at which children should be monitored.

The bulk of research to date has focused on the sources and consequences of elevated BLL at the individual level. In nationally-representative samples, nonHispanic Black children and Mexican American children have consistently exhibited higher prevalence rates of elevated BLL $(\geq 10 \mu \mathrm{g} / \mathrm{dL})$ than non-Hispanic White children (Jones et al., 2009; Pirkle et al., 1998). From 1999-2004, the prevalence rates of BLL $\geq 10 \mu \mathrm{g} / \mathrm{dL}$ among non-Hispanic Blacks, Mexican Americans, and non-Hispanic Whites were $0.03,0.01$, and 0.01 , respectively, having declined from 0.11, 0.04, and 0.02 in 1991-1994 (Jones et al., 2009). Racial disparities in BLL at the individual level have been found to be partially attributable to differences in exposure from the home environment and surrounding soil, as the homes of Black children tend to be in worse physical condition (e.g., peeling paint) than those of White children (Lanphear et al., 1996).

A small but growing body of work has considered the relationship between neighborhood characteristics, such as poverty rate or racial composition, and individuals' BLL (e.g., Lanphear et al., 1998). Only a limited number of studies have examined ecological prevalence rates of elevated BLL and their correlates, and even fewer have done so longitudinally. In Rhode Island, for example, researchers found relationships between prevalence rates of BLL $\geq 10 \mu \mathrm{g} / \mathrm{dL}$ in 1994-1996, as measured at the individual level by the Rhode Island Department of Health and aggregated by the researchers, and measures from the 1990 Census of neighborhood socioeconomic status, including poverty and unemployment rates, as well as the age of housing stock at both the block group and Census tract levels (Krieger et al., 2003a). Another study in North Carolina posited that clusters of elevated BLL in rural counties with larger Black populations stem from Black families' occupancy of deteriorating homes with lead-based paint that were first built by wealthy White families who have since moved 
away (Hanchette 2008). Nationally, a positive relationship has been found between the percentage of Black children under age sixteen and average air lead concentrations at the county level, while the percentage of White youth were found to be inversely related to air lead concentrations (Stretesky 2003). Finally, Tonny Oyana and Florence Margai (2010) identified "hot spots" of high prevalence rates of BLL $\geq 10 \mu \mathrm{g} / \mathrm{dL}$ in Chicago. The Westside, Southside, and Far Southside areas had the highest risks of elevated BLL in 1997, 2000, and 2003, and were associated with lower median household incomes, older housing stock, and higher percentages of Black, Hispanic, and Asian residents.

\section{Research Framework and Questions}

Although prior studies signal a neighborhood-level relationship between racial composition and prevalence rates of elevated BLL, important questions remain. For one, there are few systematic data on the magnitude of lead poisoning in Black communities both before and after public housing and health departments undertook largescale efforts at lead abatement in housing. The evidence we do have shows that the prevalence of lead poisoning reached extraordinary levels in certain inner-city contexts as recently as the 1990s. Oyana and Margai (2010), for example, discovered that over $75 \%$ of children in some Westside communities of Chicago surpassed CDC guidelines for BLL. We build on this finding by exploring the prevalence of lead poisoning across all neighborhoods in Chicago over a nineteen year period, 1995-2013. We document and map the geographic concentration of both initial levels and rates of decline in lead poisoning.

Second, we explore the nature of the relationship between lead toxicity and racial composition. We are guided by research on neighborhood effects and the link between the spatial foundations of inequality and racial stratification. As noted above, a longstanding finding in the United States is that Black disadvantage relative to Whites is sustained in large part by the connection between segregation and concentrated poverty—what Douglas Massey and Mitchell Eggers (1990) term the ecology of inequality. In this respect, neighborhood effects are a major source of how enduring racial inequality is produced and maintained (Sampson 2012; Sharkey 2013). The ecology of inequality has major theoretical implications for health as well, exemplified in Massey's (2004) biosocial model of stratification. He advances environmental stress as a major example of how racial inequality gets into the body to produce allostatic load. ${ }^{1}$ Specifically, the wear and tear associated with life in under-resourced and violent neighborhoods to which African Americans are disproportionately exposed are hypothesized to translate into elevated rates of physical and mental health problems, deficits in cognitive skill development, and disrupted capacity for learning. A body of recent research supports this hypothesis and shows how incidents of extreme violence undermine children's cognitive functioning and behavior in school, with consequences for short-term academic performance and long-term developmental trajectories (Sharkey and Sampson, 2015).

We extend these ideas to conceptualize toxic inequality at the neighborhood level and empirically examine the magnitude of the association between the spatial isolation of African Americans and the prevalence of lead poisoning. We also assess a set of theoretically-plausible mechanisms that may account for this association. Further, we explore the nature of neighborhood-level rates of decline in lead exposure since policy efforts to eradicate lead paint in housing were ramped up in the mid-1990s, specifically asking: (1) Has the racial gap in lead exposure remained persistent in an era of substantial declines overall? And (2) have declines been unevenly 
experienced across communities of color? By directly addressing these questions and examining the racial ecology of both persistence and change in lead toxicity across neighborhoods, we are able to decompose the critical features of a major health hazard in the contemporary era.

\section{DATA, MEASURES, AND ANALYTIC STRATEGY}

We begin by painting a descriptive portrait of the prevalence of elevated BLL in Chicago across neighborhoods and over time. To measure neighborhood-level lead toxicity, we use lead test results from the Chicago Department of Public Health $(\mathrm{CDPH})$ for all children ages one through five tested for lead exposure by "block group" and year from 1995-2013. Block groups are relatively compact groupings, in ecological terms, and include just over 1000 people, on average, in Chicago, making them an appropriate unit for examining neighborhood-level exposure to lead. The BLLs of children in Chicago are tested following a recommended schedule of four tests by thirty-six months of age, with additional testing until six years of age if needed. The majority of lead tests are conducted using venous blood samples, and the remainder using capillary blood samples. The CDPH data include approximately 77,500 lead tests per year, ranging from 54,703 in 1995 to 84,232 in 2009, with an average of thirty-three $(\mathrm{SD}=32$ ) lead tests per block group per year. The data allow us to estimate the number of children in each block group-year with BLL $\geq 6 \mu \mathrm{g} / \mathrm{dL}$ and BLL $\geq 10 \mu \mathrm{g} / \mathrm{dL}$. In light of the CDC's most recent recommendation of BLL $\geq 5 \mu \mathrm{g} / \mathrm{dL}$ as the level "of concern" as well as recent findings indicating the consequences of low levels of exposure (Chiodo et al., 2004), we focus on children with BLL $\geq 6 \mu \mathrm{g} / \mathrm{dL}$. For comparison, we also calculated yearly block group-level prevalence rates of $\mathrm{BLL} \geq 10 \mu \mathrm{g} / \mathrm{dL}$.

To examine variation in the prevalence rates of elevated BLL across Chicago's neighborhoods, we map the prevalence rates of BLL $\geq 6 \mu \mathrm{g} / \mathrm{dL}$ for the 2223 block groups for which we have CDPH data for 1995. To examine change in prevalence rates over time, we then convert each block group's annual prevalence rates (45,229 block group-year pairs) to annual prevalence rates using a three-year moving average. We use these moving averages to calculate average block group-level prevalence rates of elevated BLL for each year, 1996-2012.

Having uncovered the overall neighborhood-level trend in lead toxicity over time, we next begin to unpack whether and how this trend varies by neighborhoodlevel racial composition. We matched our block group-level prevalence rates of elevated BLL to block group data on racial/ethnic composition, obtained from the 1990 Decennial Census, and calculated the proportion of individuals in each block group who identify as non-Hispanic White, as non-Hispanic Black, or as Hispanic. We then calculate average, neighborhood-level prevalence rates for each year, stratified by neighborhood racial/ethnic composition (44,681 block group-year pairs), measured by whether block groups are predominantly $(\geq 70 \%)$ non-Hispanic White (29.3\% of block group-year pairs), non-Hispanic Black (38.2\% of block group-year pairs), or Hispanic (6.8\% of block group-year pairs). Since absolute levels of prevalence rates changed across our study period, we also examine which block groups fall within each year's top quintile of prevalence rates, allowing for a consistent comparison of the racial/ethnic compositions of the neighborhoods with the highest elevated BLL over time.

In the second phase of our analysis, we use hierarchical linear models (HLM) to assess whether neighborhoods' longitudinal trajectories of prevalence vary significantly 
by their racial compositions, as well as whether the baseline racial gaps in lead exposure we observe are due to three classes of structural mechanisms-(a) socioeconomic factors such as poverty and education; (b) housing characteristics such as unit age, dilapidation, and vacancies; and (c) environmental hazards such as proximity to industrial smelting plants or freeways. Consistent with our theoretical objective, HLM allows us to parse out variation due to these factors in neighborhoods' initial levels of lead exposure from variation in neighborhoods' trajectories of exposure over time. ${ }^{2}$

\section{Structural Covariates and Mechanisms}

One hypothesis for explaining racial disparities in exposure to environmental hazards looks to differences in income and social class (Crowder and Downey, 2010; Downey 2006). To measure neighborhood socioeconomic composition (SES), we use the 1990 Decennial Census to calculate the percentage of individuals below the poverty line, the percentage of individuals with at least a bachelor's degree, and the percentage of owner-occupied housing units for each block group. The latter is an indicator of wealth and resources as well as residents' investment in the neighborhood. Meanwhile, theoretical perspectives on neighborhood stratification and racial discrimination (e.g., Massey and Denton, 1993; Sharkey 2013) lead us to also expect that racial segregation is directly linked to institutional disinvestment, older housing stock, and dilapidated housing structures - known risk factors for lead poisoning-even controlling for SES. We thus expect housing-related factors to independently account for some of the racial differences in levels of lead poisoning beyond SES factors. We assess two direct measures of the physical housing environment: the percentage of housing structures built before 1950 and the percentage of vacant housing units. The former is an established proxy for the presence of lead-based paint (Kaplowitz et al., 2010).

For the subset of our data for which they are available, we also include an indicator of which block groups contained public housing projects before they were torn down in the late 1990s as well as two measures of disinvestment and physical disrepair based on the Systematic Social Observation (SSO) component of the Project on Human Development in Chicago Neighborhoods (PHDCN) (see Sampson 2012, pp. 88-90). In 1995, the same year as our baseline blood tests, 23,816 face blocks were observed and videorecorded for an average of almost fifty face blocks per block group. We examine the contribution to lead toxicity from physical decay resulting from institutional disinvestment. The decay scale was derived from coding the observation logs and video for evidence of any of the following conditions: vacant houses; burned out, boarded up, or abandoned commercial/industrial buildings; burned out, boarded up, or abandoned houses; badly-deteriorated residential units; and badly-deteriorated recreational facilities. ${ }^{3}$ Physical disorder is another indicator of physical disinvestment, defined by a scale based on ten items that capture the presence or absence of: cigarettes or cigars in the street or gutter; garbage or litter on the street or sidewalk; empty beer bottles visible in the street; tagging graffiti; graffiti painted over; gang graffiti; political message graffiti; abandoned cars; condoms on the sidewalk; and needles/syringes on the sidewalk. For each scale, a multi-level measurement model was used to adjust for item severity and time of day observed. The resulting empirical Bayes estimates are pulled toward zero, proportional to their unreliability, which corrects for bias in the measures. ${ }^{4}$ The physical decay scale ranges from -1.43 to 2.93 , and the physical disorder scale from -2.15 to 1.89. Although positively related $(\mathrm{r}=0.40)$, the data permit assessment of how physical decay and physical disorder relate independently to lead toxicity.

Even with similar socioeconomic, housing, and physical disorder conditions, theoretical perspectives on environmental racism lead us to additionally examine the 
differential locations of industries and other features of the urban landscape that historically have been linked to environmental hazards (e.g., Crowder and Downey, 2010; Downey 2006). In our case, airborne lead emitted from smelting plants and car emissions become salient because lead lodges in the soil with very slow decay, constituting a direct exposure risk for children playing in backyards and parks (Needleman and Bellinger, 1991). We thus geocoded the locations of smelting plants that produced lead-based toxins and assessed which block groups either contained these plants or were adjacent to block groups containing these plants. ${ }^{5}$ Additionally, we used a 2009 U.S. and Canada Highways shapefile along with ArcGIS to calculate the percentage of each block group that falls within a 0.1 mile radius of Chicago's major highways as a proxy for automobile emissions that built up in the soil before leaded gasoline was banned in the late 1970s.

By testing each of these three classes of mechanisms, we are able to determine multiple pathways by which Chicago's racial ecology relates to lead poisoning, including whether racial stratification by neighborhood continues to matter even after adjusting for structural correlates. Our model, by class of measure, can be written formally as:

(1) $(\text { Prevalence of BLL } \geq 6 \mu \mathrm{g} / \mathrm{dL})_{\mathrm{tj}}=\beta_{0 \mathrm{j}}+\beta_{1 \mathrm{j}}\left(\mathrm{Year}_{\mathrm{tj}}-1995\right)+\beta_{2 \mathrm{j}}\left(\mathrm{Year}_{\mathrm{tj}}-1995\right)^{2}+\varepsilon_{\mathrm{tj}}$

(2) $\beta_{0 j}=\gamma_{00}+\gamma_{01}\left(\right.$ racial composition $\left._{\mathrm{j}}\right)+\gamma_{02}\left(\right.$ socioeconomic composition $\left._{\mathrm{j}}\right)+\gamma_{03}($ (housing characteristics $\left._{\mathrm{j}}\right)+\gamma_{04}\left(\right.$ environmental hazards $\left._{\mathrm{j}}\right)+\mu_{0 j}$

(3) $\beta_{1 j}=\gamma_{10}+\gamma_{11}\left(\right.$ racial $\left._{\text {composition }}\right)+\gamma_{12}\left(\right.$ socioeconomic composition $\left._{\mathrm{j}}\right)+\gamma_{13}($ housing characteristics $\left._{j}\right)+\gamma_{14}\left(\right.$ environmental hazards $\left._{j}\right)+\mu_{1 j}$

(4) $\beta_{2 j}=\gamma_{20}+\gamma_{21}\left(\right.$ racial composition $\left._{j}\right)+\gamma_{22}\left(\right.$ socioeconomic composition $\left._{\mathrm{j}}\right)+\gamma_{23}$ (housing characteristics $\left._{j}\right)+\gamma_{24}\left(\right.$ environmental hazards $\left._{j}\right)+\mu_{2 j}$

Each neighborhood $j$ 's initial prevalence rate $\left(\beta_{0 j}\right)$ and its changes in prevalence over time $\left(\beta_{1 \mathrm{j}}+\beta_{2 \mathrm{j}}\right)$ are functions of vectors of covariates indicating the neighborhood's racial composition $\left(\gamma_{01}\right.$ or $\gamma_{11}+\gamma_{21}$, respectively), socioeconomic composition $\left(\gamma_{02}\right.$ or $\gamma_{12}+\gamma_{22}$, respectively), housing characteristics ( $\gamma_{03}$ or $\gamma_{13}+\gamma_{23}$, respectively), and environmental hazards ( $\gamma_{04}$ or $\gamma_{14}+\gamma_{24}$, respectively). Time is measured in years indexed by $t$ and centered at $1995\left(\right.$ Year $\left._{t j}-1995\right)$, so that the intercept $\left(\beta_{0 j}\right)$ can be interpreted as the average neighborhood-level prevalence rate at the start of the study period, with all covariates held at zero. We also include a polynomial specification of time $\left(\left(\mathrm{Year}_{\mathrm{tj}}-1995\right)^{2}\right)$, given the shape of the relationship between neighborhood-level prevalence rates of elevated BLL and time. Our HLM models employ 44,458 block group-year pairs from 2376 block groups for which we have complete information on all covariates, with the exception of our model that includes measures from the SSO study of the PHDCN, which employs 9031 block group-year pairs from 480 block groups. ${ }^{6}$

Finally, to ease interpretation of our coefficients of interest considering the complexity of the HLM models, we calculate predicted neighborhood-level prevalence rates of elevated BLL for varying percentages of non-Hispanic Black and Hispanic residents in 1995 and in 2010, holding all other continuous covariates at their means and categorical covariates at their modes.

\section{THE LANDSCAPE OF LEAD EXPOSURE IN CHICAGO}

Figure 1 reveals that, in 1995, Chicago neighborhoods exhibited stark variability in children's prevalence rates of elevated BLL $(\geq 6 \mu \mathrm{g} / \mathrm{dL})$. Indeed, prevalence rates ranged from 0.24 to a remarkable 0.96 among neighborhoods where the BLL of at least fifty children were tested. The overall preponderance of neighborhoods with prevalence rates of at least 0.51 is alarming, given the consequences of even low levels 


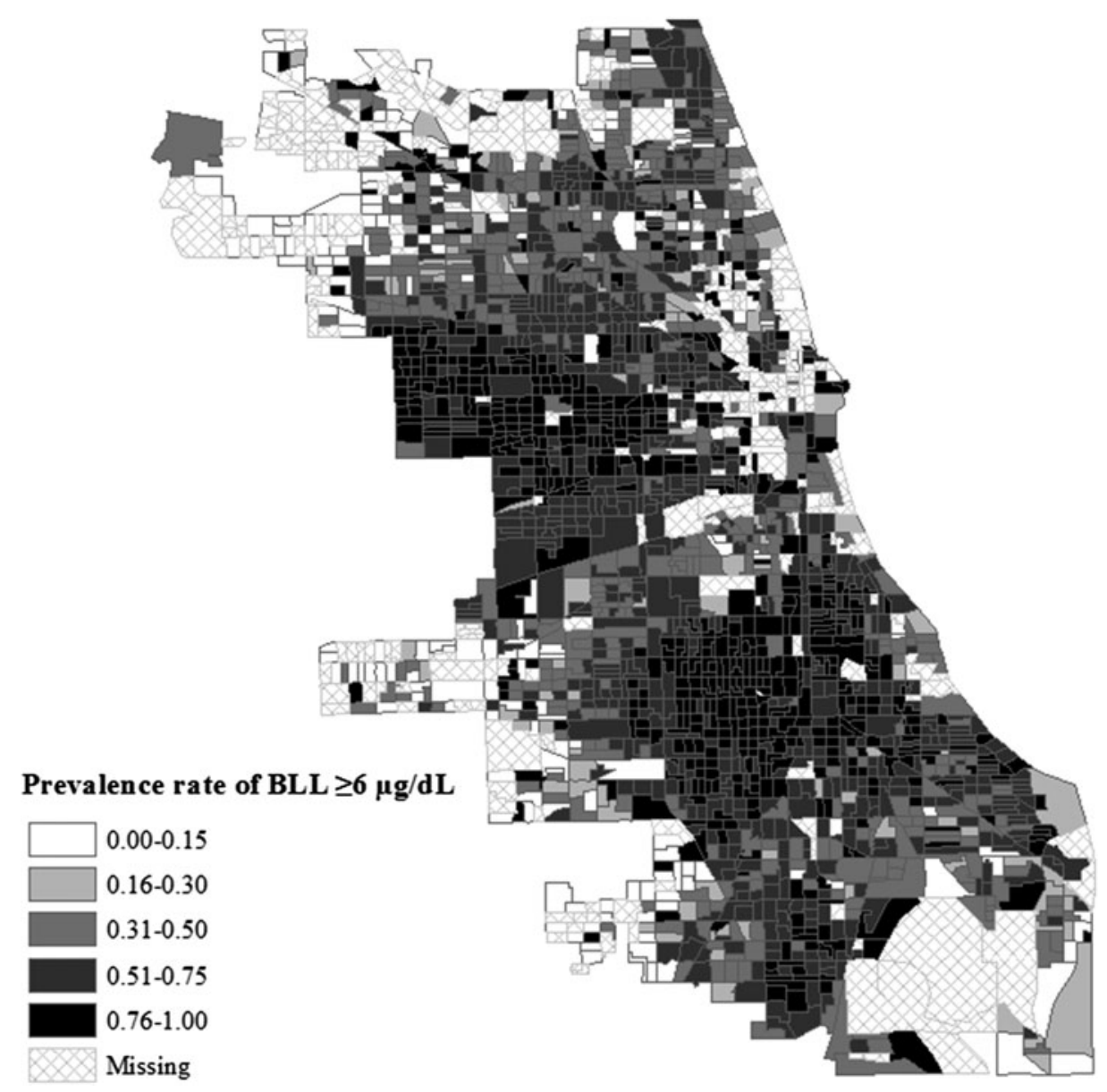

Fig. 1. Prevalence Rates of Elevated BLL for Chicago Block Groups, 1995.

of lead exposure for developmental health. Furthermore, in line with Oyana's and Margai's (2010) findings, neighborhoods with particularly high prevalence rates of at least 0.76 appear to be clustered in the west and Southside areas of the city, which are also predominantly Black.

In the two decades following 1995, however, neighborhood prevalence rates of elevated BLL fell substantially and converged toward zero (Figure 2). While the average neighborhood-level prevalence rate of BLL $\geq 6 \mu \mathrm{g} / \mathrm{dL}$ was 0.48 in 1996, by 2012, it was 0.03 . Similarly, the average prevalence rate of BLL $\geq 10 \mu \mathrm{g} / \mathrm{dL}$, a more acute measure of exposure, fell from 0.26 in 1996 to 0.01 in 2012. These very large declines of $94 \%$ and $96 \%$, respectively, reflect Chicago's increased hazard control through lead remediation and the enclosure of lead-based paint, coinciding with the start of our study period. Still, the city's efforts do not fully explain the decline, as at least some exposure at lower BLLs comes from soil outside of the home, which became contaminated with lead from the home's paint and from historical pollution from cars and industries. Nonetheless, a map for 2013 similar to the one shown in Figure 1 indicates many fewer hot spots of exposure (not shown).

How do neighborhoods' initial prevalence rates as well as their trajectories of declining prevalence relate to their racial compositions? Figure 3 stratifies the prevalence rates of BLL $\geq 6 \mu \mathrm{g} / \mathrm{dL}$ shown in Figure 2 by neighborhood racial composition. ${ }^{7}$ 
The Racial Ecology of Lead Poisoning

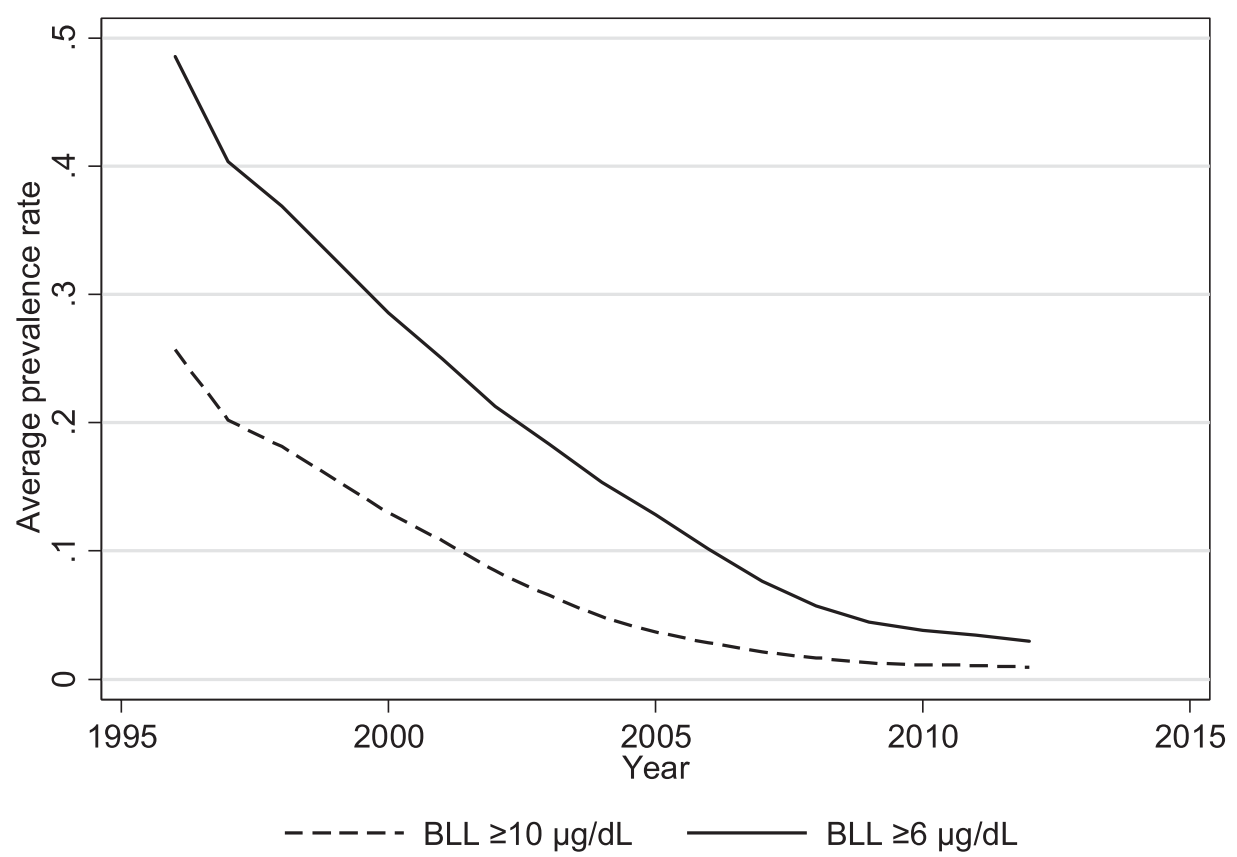

Fig. 2. Average Block-Group Prevalence Rates of Elevated BLL, 1995-2013.

From the figure, it is apparent that predominantly Black neighborhoods consistently exhibit the highest prevalence rates of elevated BLL across our study period, while predominantly White neighborhoods consistently exhibit the lowest prevalence rates. The prevalence rates of predominantly Hispanic neighborhoods are in-between.

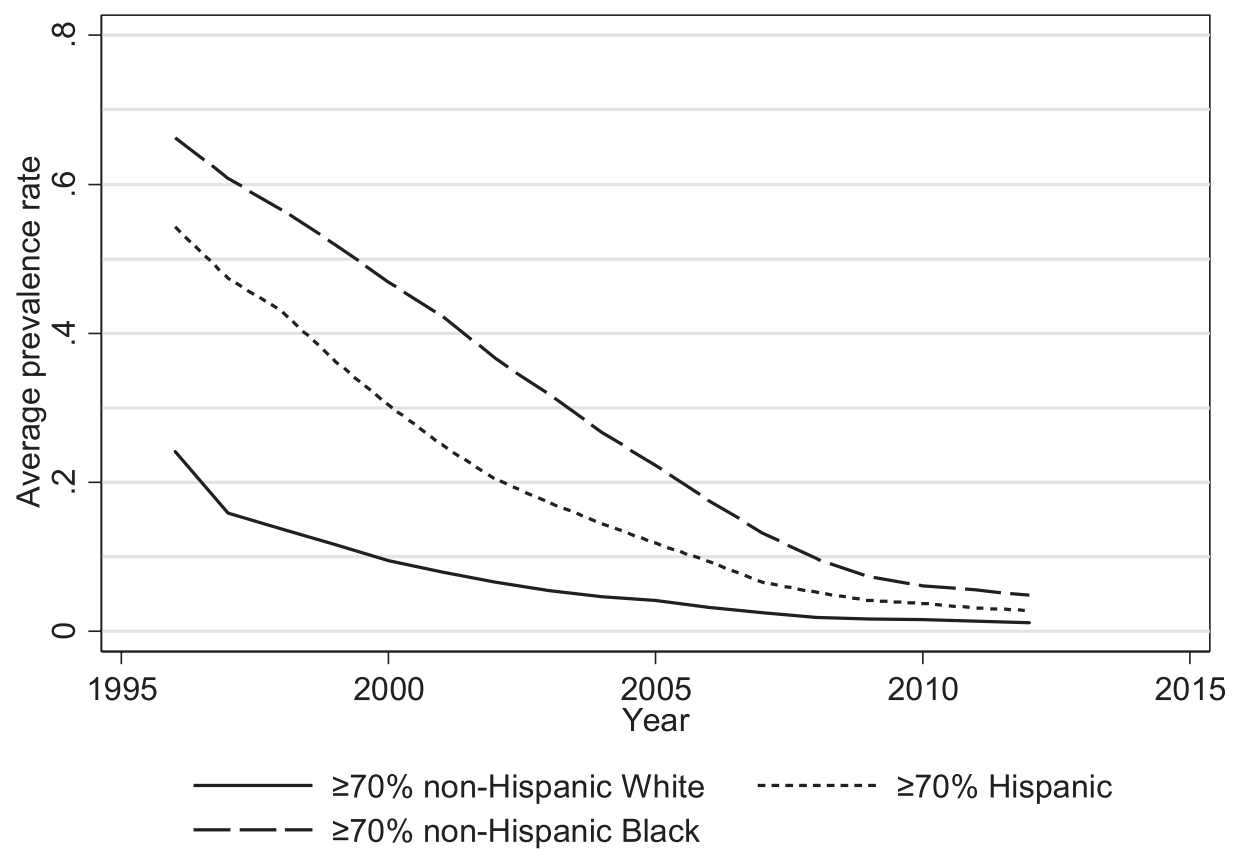

Fig. 3. Average Block-Group Prevalence Rates of Elevated BLL ( $\geq 6 \mu \mathrm{g} / \mathrm{Dl})$, by Racial Composition of Block Groups. 
The disparities are especially large at the beginning of the period and shrink considerably over time. The difference between the prevalence rates of Black neighborhoods and White neighborhoods in 1996 is 0.42 , while the difference between Hispanic and White neighborhoods is 0.30 ; by 2012, the differences shrink to 0.04 and 0.02 , respectively. There is, therefore, variation in the magnitude and speed of declining prevalence rates by neighborhood. In line with national estimates at the individual level (Jones et al., 2009), and given their higher initial prevalence rates, the prevalence rates of elevated BLL in Black neighborhoods decline more and more rapidly than those of predominantly White neighborhoods.

Despite shrinking racial disparities in rates of elevated BLL between 1995 and 2013, Figure 4 reveals a striking persistence in which neighborhoods experience the highest rates of elevated BLL after adjusting for the decline in absolute prevalence rates. Predominantly Black neighborhoods comprise the vast majority of neighborhoods in the top quintile of prevalence rates in each year, from 1996 through 2012. Although this inequality begins to decline after 2005, by 2012, the top quintile was still largely (75\%) comprised of predominantly Black neighborhoods. Taken together, Figures 3 and 4 show that Chicago's Black and, to a lesser extent, Hispanic neighborhoods disproportionately bear the burden of the city's lead toxicity. But Figure 3 simultaneously reveals the power of a universal public health policy to reduce racial inequities when minority neighborhoods are disproportionately saddled with risk.

\section{DECOMPOSING PERSISTENCE AND CHANGE}

In order to more precisely parse out variation in neighborhoods' initial prevalence rates of elevated BLL from variation in their trajectories of prevalence over time, as well as to assess plausible mechanisms that may account for the racial disparities we observe in

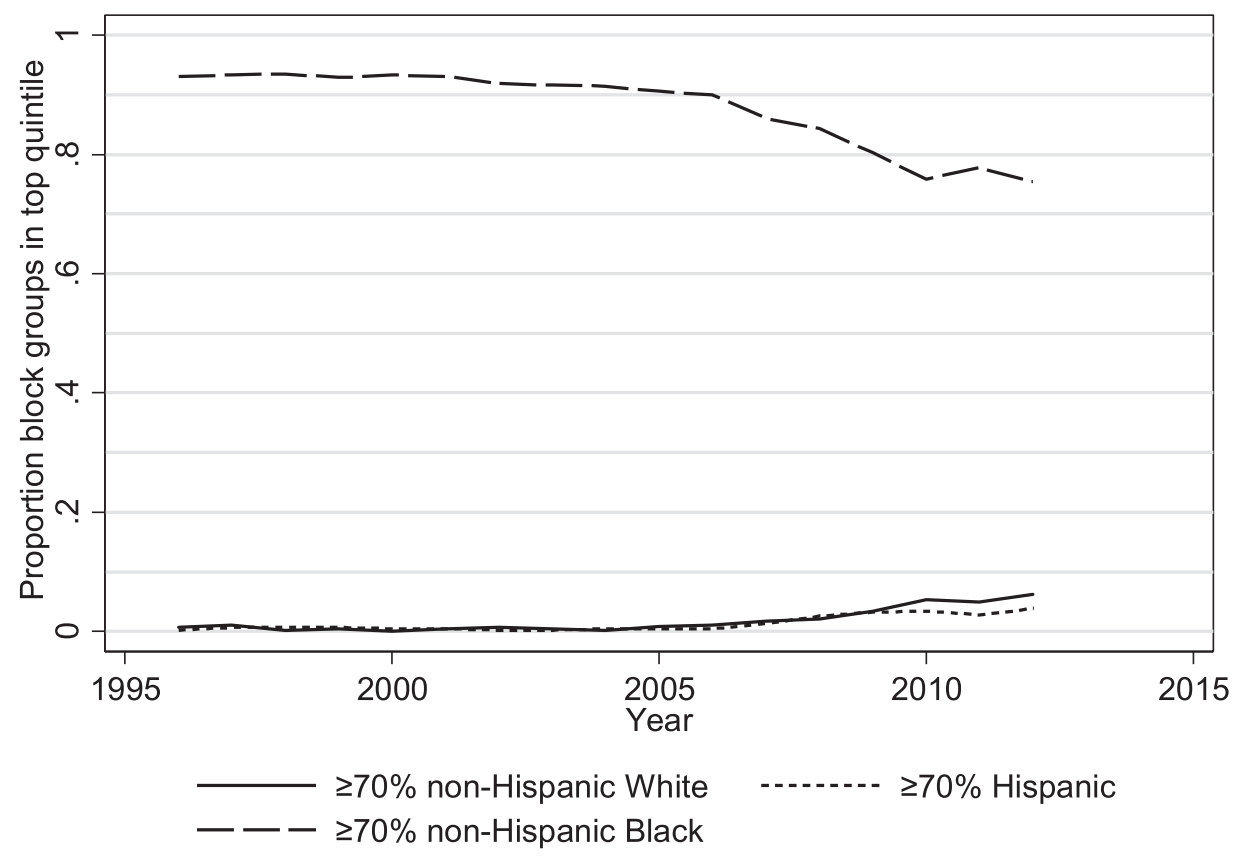

Fig. 4. Proportion of Block Groups in Top Quintile of Elevated BLL ( $\geq 6 \mu \mathrm{g} / \mathrm{Dl})$ Rates that are Predominantly Non-Hispanic White, Non-Hispanic Black, or Hispanic, by Year. 
Figures 3 and 4, we now turn to the results from our hierarchical linear regression models. A substantial portion-24\% - of the total variation in children's prevalence rates of elevated BLL across our study period is attributable to differences between, as opposed to within, Chicago neighborhoods, and most of this between-neighborhood variation is due to differences in initial prevalence rates, as opposed to differences in neighborhoods' rates of change over time. This initial finding, based on a random effects model and an unconditional growth model in which time is the only covariate (not shown), corroborate our findings in Figures 2 and 3 that neighborhoods exhibited large racial disparities in their prevalence rates at the start of the period but that neighborhood-level prevalence fell considerably between 1996 and 2012 across all neighborhoods. Furthermore, declining prevalence over time accounts for $76 \%$ of the within-neighborhood variation in prevalence.

Our main interest is in explaining between-neighborhood variation, particularly at the start of the period. Model 1 (Table 1) confirms that neighborhoods exhibit statistically significant racial disparities in their prevalence rates of elevated BLL at baseline. Given our research framework that is grounded in the history of racial segregation in the United States, we simultaneously control for the block group percentage of individuals who were not born in the United States to account for the varying social forces that constrain neighborhoods with large immigrant populations. With this control, neighborhoods with higher percentages of non-Hispanic Blacks and with higher percentages of Hispanics still have significantly higher initial prevalence rates of elevated BLL and exhibit significantly faster declines in prevalence across the period relative to neighborhoods with higher percentages of non-Hispanic Whites. With respect to neighborhoods' initial prevalence rates of elevated BLL, a one percentage increase in the non-Hispanic Black population and a one percentage increase in the Hispanic population are associated with $0.56 \%$ and $0.47 \%$ increases in children's prevalence rates, respectively. Meanwhile, the relationship between neighborhoods' racial compositions and the speeds of their prevalence rates' declines are much smaller in magnitude.

As noted above, racial disparities in lead exposure may be at least partially attributable to neighborhood socioeconomic composition. Race and poverty status are associated with one another in the United States, particularly at the neighborhood level, and family socioeconomic resources are linked to children's lead exposure. To assess whether these relationships account for the neighborhood-level racial disparities in lead exposure in our data, Model 2 adds indicators of neighborhood socioeconomic composition. We find that neighborhoods with higher percentages of individuals below the poverty line have significantly higher initial prevalence rates of elevated BLL but that, interestingly, their prevalence rates do not necessarily decline faster over time relative to less poor neighborhoods. ${ }^{8}$ In addition, a higher percentage of individuals with at least a college degree, as well as a higher percentage of home ownership, are each independently associated with a lower initial prevalence rate of elevated BLL and, with respect to the latter, in turn, a slower decline in prevalence. ${ }^{9}$ These results are consistent with the well-documented gradient between neighborhood socioeconomic status and health (Krieger et al., 2003b). However, while socioeconomic composition accounts for part of the relationship between racial composition and prevalence rates, the percentages of non-Hispanic Black and Hispanic residents still exhibit robust relationships with neighborhood-level prevalence rates of elevated BLL, both initially and over time.

Given their spatial and not just socioeconomic stratification, we also hypothesized that Blacks and Hispanics are disproportionately exposed to older housing with deteriorating lead-based paint and to neighborhoods that contain dilapidated housing 
Table 1. Coefficients and 95\% Confidence Intervals from Hierarchical Linear Models Showing Associations with Neighborhood Prevalence Rates of Elevated BLL $(\geq 6 \mu \mathrm{g} / \mathrm{dL})$

\begin{tabular}{|c|c|c|c|c|c|}
\hline & Model 1 & Model 2 & Model 3 & Model 4 & Model 5 \\
\hline \multicolumn{6}{|l|}{ Fixed Effects } \\
\hline \multicolumn{6}{|l|}{$\overline{\text { Initial prevalence rate }}$} \\
\hline Intercept & $\begin{array}{l}0.1913^{* * *} \\
(0.1776,0.2050)\end{array}$ & $\begin{array}{l}0.3656^{\text {*** }} \\
(0.3387,0.3926)\end{array}$ & $\begin{array}{l}0.1615^{\text {*** }} \\
(0.1335,0.1895)\end{array}$ & $\begin{array}{l}0.1680^{* * *} \\
(0.1402,0.1958)\end{array}$ & $\begin{array}{l}0.3166^{* * *} \\
(0.2647,0.3685)\end{array}$ \\
\hline Percent non-Hispanic Black & $\begin{array}{l}0.5558^{* * *} \\
(0.5396,0.5721)\end{array}$ & $\begin{array}{l}0.4423^{* * *} \\
(0.4238,0.4608)\end{array}$ & $\begin{array}{l}0.4379^{* * *} \\
(0.4217,0.4540)\end{array}$ & $\begin{array}{l}0.4424^{* * *} \\
(0.4265,0.4584)\end{array}$ & $\begin{array}{l}0.3683^{* * *} \\
(0.3363,0.4003)\end{array}$ \\
\hline Percent Hispanic & $\begin{array}{l}0.4655^{* * *} \\
(0.4376,0.4933)\end{array}$ & $\begin{array}{l}0.3418^{* * *} \\
(0.3135,0.3701)\end{array}$ & $\begin{array}{l}0.2576^{* * *} \\
(0.2323,0.2829)\end{array}$ & $\begin{array}{l}0.2510^{* * *} \\
(0.2260,0.2760)\end{array}$ & $\begin{array}{l}0.1895^{* * *} \\
(0.1450,0.2339)\end{array}$ \\
\hline Percent Foreign Born & $\begin{array}{l}0.1208^{* * *} \\
(0.0676,0.1739)\end{array}$ & $\begin{array}{l}0.0250 \\
(-0.0244,0.0745)\end{array}$ & $\begin{array}{l}0.0394 \\
(-0.0039,0.0827)\end{array}$ & $\begin{array}{l}0.0477^{*} \\
(0.0050,0.0904)\end{array}$ & $\begin{array}{l}0.0149 \\
(-0.0605,0.0904)\end{array}$ \\
\hline Percent Below Poverty & & $\begin{array}{l}0.0812^{\text {** }} \\
(0.0425,0.1199)\end{array}$ & $\begin{array}{l}0.1232^{* \star *} \\
(0.0888,0.1577)\end{array}$ & $\begin{array}{l}0.1137^{* * *} \\
(0.0796,0.1477)\end{array}$ & $\begin{array}{l}0.0089 \\
(-0.0605,0.0783)\end{array}$ \\
\hline Percent $\geq$ Bachelor's Degree & & $\begin{array}{l}-0.1767^{* * *} \\
(-0.2119,-0.1415)\end{array}$ & $\begin{array}{l}-0.1799^{* * *} \\
(-0.2106,-0.1492)\end{array}$ & $\begin{array}{l}-0.1801^{* * *} \\
(-0.2104,-0.1499)\end{array}$ & $\begin{array}{l}-0.2480^{* * *} \\
(-0.3126,-0.1835)\end{array}$ \\
\hline Percent Owner Occupied & & $\begin{array}{l}-0.1737^{* * *} \\
(-0.1980,-0.1493)\end{array}$ & $\begin{array}{l}-0.0909^{* * *} \\
(-0.1136,-0.0682)\end{array}$ & $\begin{array}{l}-0.0927^{* * *} \\
(-0.1150,-0.0703)\end{array}$ & $\begin{array}{l}-0.0713^{* *} \\
(-0.1181,-0.0245)\end{array}$ \\
\hline Percent Housing Structures Built Before 1950 & & & $\begin{array}{l}0.2474^{* * *} \\
(0.2287,0.2661)\end{array}$ & $\begin{array}{l}0.2421^{* * *} \\
(0.2236,0.2606)\end{array}$ & $\begin{array}{l}0.0913^{* * *} \\
(0.0561,0.1264)\end{array}$ \\
\hline Percent Housing Units Vacant & & & $\begin{array}{l}0.2170^{* * *} \\
(0.1546,0.2793)\end{array}$ & $\begin{array}{l}0.2200^{* * *} \\
(0.1585,0.2816)\end{array}$ & $\begin{array}{l}0.4586^{* * *} \\
(0.3294,0.5878)\end{array}$ \\
\hline
\end{tabular}


Table 1. continued

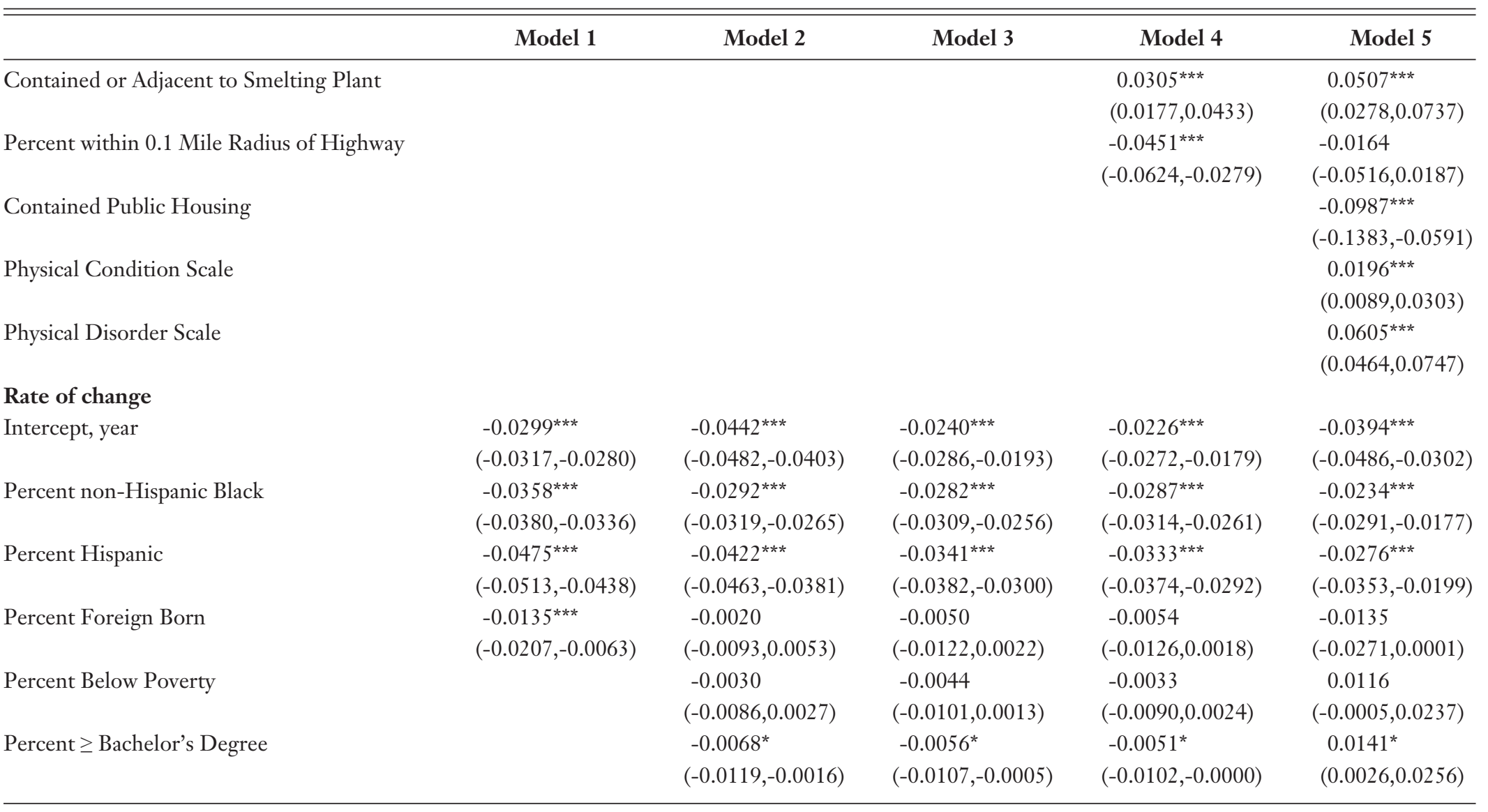


Table 1. continued

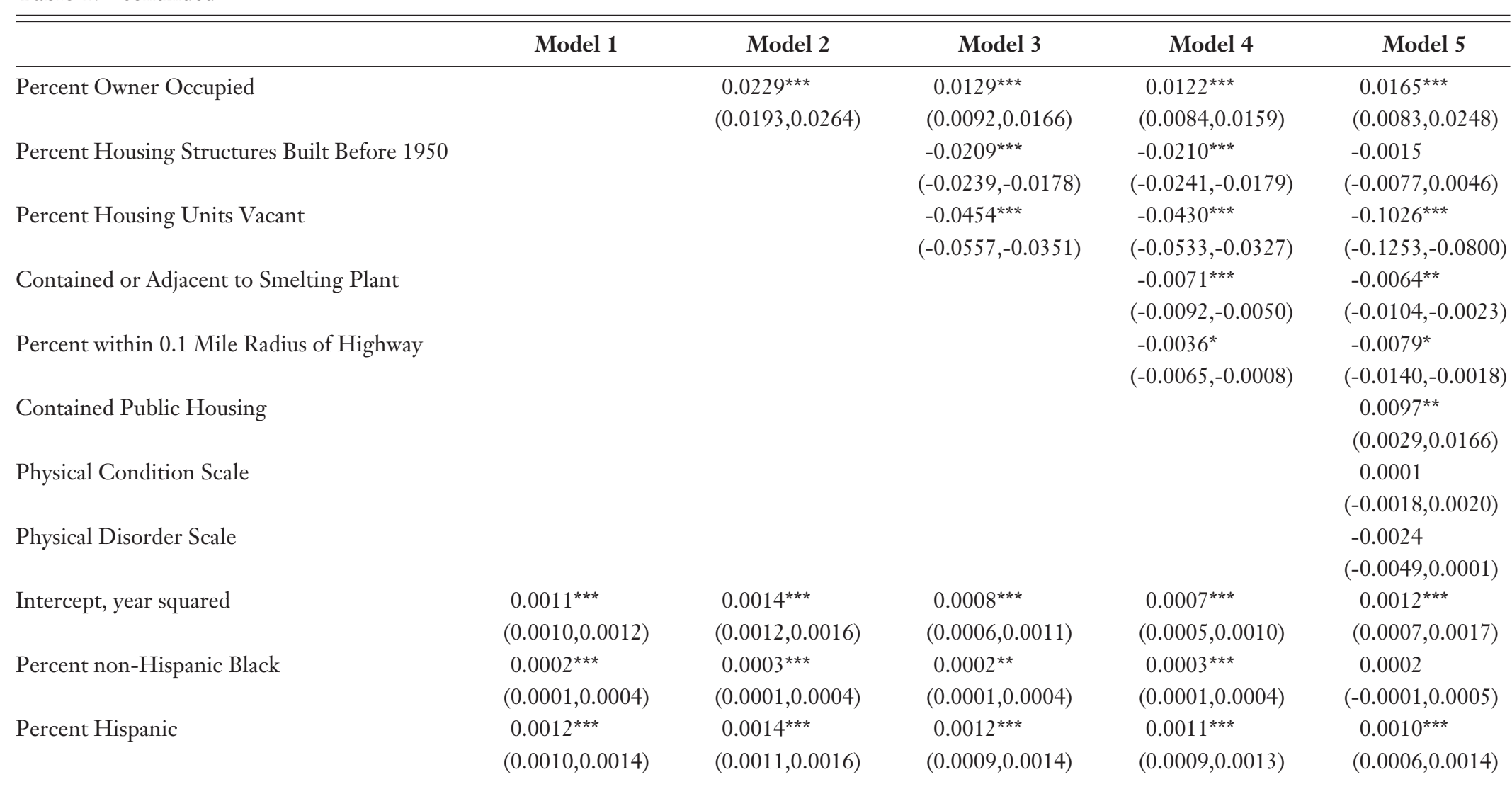


Table 1. continued

\begin{tabular}{|c|c|c|c|c|c|}
\hline & Model 1 & Model 2 & Model 3 & Model 4 & Model 5 \\
\hline Percent Foreign Born & $\begin{array}{l}0.0005^{* *} \\
(0.0001,0.0009)\end{array}$ & $\begin{array}{l}0.0002 \\
(-0.0002,0.0005)\end{array}$ & $\begin{array}{l}0.0003 \\
(-0.0001,0.0007)\end{array}$ & $\begin{array}{l}0.0003 \\
(-0.0001,0.0007)\end{array}$ & $\begin{array}{l}0.0010^{* *} \\
(0.0003,0.0017)\end{array}$ \\
\hline Percent Below Poverty & & $\begin{array}{l}-0.0002 \\
(-0.0005,0.0001)\end{array}$ & $\begin{array}{l}-0.0002 \\
(-0.0005,0.0001)\end{array}$ & $\begin{array}{l}-0.0003 \\
(-0.0006,0.0000)\end{array}$ & $\begin{array}{l}-0.0008^{*} \\
(-0.0014,-0.0001)\end{array}$ \\
\hline Percent $\geq$ Bachelor's Degree & & $\begin{array}{l}0.0011^{* * *} \\
(0.0008,0.0013)\end{array}$ & $\begin{array}{l}0.0010^{* * *} \\
(0.0007,0.0013)\end{array}$ & $\begin{array}{l}0.0010^{* * *} \\
(0.0007,0.0013)\end{array}$ & $\begin{array}{l}0.0002 \\
(-0.0005,0.0008)\end{array}$ \\
\hline Percent Owner Occupied & & $\begin{array}{l}-0.0007^{* * *} \\
(-0.0009,-0.0006)\end{array}$ & $\begin{array}{l}-0.0004^{* * *} \\
(-0.0006,-0.0002)\end{array}$ & $\begin{array}{l}-0.0004^{* * *} \\
(-0.0006,-0.0002)\end{array}$ & $\begin{array}{l}-0.0007^{* *} \\
(-0.0011,-0.0002)\end{array}$ \\
\hline Percent Housing Structures Built Before 1950 & & & $\begin{array}{l}0.0004^{* * *} \\
(0.0003,0.0006)\end{array}$ & $\begin{array}{l}0.0005^{\text {*** }} \\
(0.0003,0.0006)\end{array}$ & $\begin{array}{l}-0.0002 \\
(-0.0005,0.0001)\end{array}$ \\
\hline Percent Housing Units Vacant & & & $\begin{array}{l}0.0019^{* * *} \\
(0.0014,0.0025)\end{array}$ & $\begin{array}{l}0.0018^{* * *} \\
(0.0012,0.0023)\end{array}$ & $\begin{array}{l}0.0046^{* * *} \\
(0.0033,0.0058)\end{array}$ \\
\hline Contained or Adjacent to Smelting Plant & & & & $\begin{array}{l}0.0003^{* * *} \\
(0.0002,0.0005)\end{array}$ & $\begin{array}{l}0.0002^{*} \\
(<0.0000,0.0005)\end{array}$ \\
\hline Percent within 0.1 Mile Radius of Highway & & & & $\begin{array}{l}0.0004^{* * *} \\
(0.0002,0.0005)\end{array}$ & $\begin{array}{l}0.0005^{* *} \\
(0.0002,0.0008)\end{array}$ \\
\hline Contained Public Housing & & & & & $\begin{array}{l}-0.0003 \\
(-0.0007,0.0001)\end{array}$ \\
\hline Physical Condition Scale & & & & & $\begin{array}{l}-0.0001 \\
(-0.0002,<0.0000)\end{array}$ \\
\hline Physical Disorder Scale & & & & & $\begin{array}{l}-0.0001 \\
(-0.0002,0.0001)\end{array}$ \\
\hline
\end{tabular}


Table 1. continued

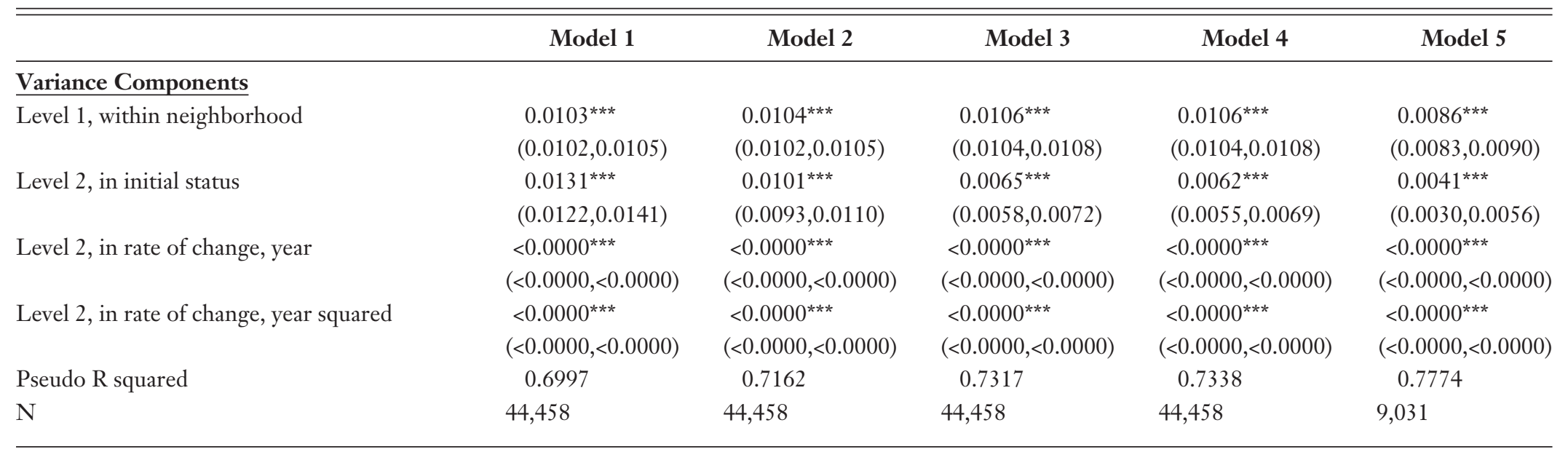

${ }^{*} \mathrm{p}<.05{ }^{* *} \mathrm{p}<.01{ }^{* * *} \mathrm{p}<.001$. 
structures that contribute lead to the soil. Therefore, in Model 3, we examine the percentage of housing structures that were built before 1950 and the percentage of housing structures that are vacant to examine whether these mechanisms account for racial disparities in elevated BLL that are not already explained by neighborhoods' socioeconomic status. Paint used in housing built before 1950 included higher lead levels than are considered safe today, and the remnants of these paints may still be found under more recent layers of peeling paint, in house dust, and in the soil surrounding these homes. Meanwhile, high vacancy rates often coincide with deteriorating buildings, which can similarly expose old, lead-based paint.

In support of these expectations, Model 3 reveals that a higher percentage of housing structures built before 1950, as well as a higher percentage of vacant housing units, are each significantly associated with higher initial prevalence rates of elevated BLL and, in fact, account for approximately $36 \%$ of the between-neighborhood variance in initial prevalence rates that remains after controlling for the factors in Model 2. In line with the general trend of neighborhoods across the city, neighborhoods with higher percentages of older housing structures and of vacant units also exhibit faster declines in their prevalence rates over time. Although the physical housing environment is thus another mechanism that helps to explain racial disparities in lead toxicity, the results show that significant racial disparities remain.

We turn next to our measures of historical land use, as Black and Hispanic neighborhoods are hypothesized to disproportionately contain toxins that have built up in the soil from manufacturing plants or highway congestion. Before the Clean Air Act and other rules enacted by the Environmental Protection Agency, smelting plants and automobiles gave off emissions that contained high levels of lead particles. In Model 4, we see that neighborhoods that either contained a smelting plant or are adjacent to neighborhoods that contained a smelting plant are associated with initial prevalence rates of elevated BLL that are, on average, $0.03 \%$ higher than those of other neighborhoods and a faster decline in prevalence over time. Meanwhile, increased exposure to highway traffic is also associated with a slightly faster decline but with slightly lower initial prevalence rates. ${ }^{10}$ This counterintuitive finding is more readily understood in light of the fact that Chicago's major highways cut across advantaged as well as disadvantaged neighborhoods. Therefore, while former emissions from smelting plants influence neighborhoods' lead toxicity in the expected direction beyond socioeconomic status and the physical housing environment, our measure of highway proximity may be capturing more contemporary neighborhood processes associated with neighborhood advantage. Together, measures of historical land use explain little of the betweenneighborhood variance in initial prevalence rates and do not explain racial disparities in lead toxicity either at baseline or over time.

In a final model, we incorporate our additional measures of the physical structures of housing and neighborhood that are only available for the subset of the data covered by the PHDCN's SSO component. First, we find that the presence of public housing projects in a neighborhood is significantly associated with a lower initial prevalence rate of elevated BLL and a slightly slower rate of decline. ${ }^{11}$ Most of Chicago's public housing towers were built in the 1950s and early 1960s, and so this may be due to the Chicago Housing Authority's use of lead-free paint and/or failure to paint the interiors of its public housing developments. Second, our measures of neighborhoods' physical decay and physical disorder are each substantially associated with higher initial prevalence rates of elevated BLL but do not impact rates of declining prevalence. Yet, these measures still do not fully account for racial disparities in lead toxicity. Comparing results from Model 5 with results from Model 1 when Model 1 is run for the subset of the data that is employed in Model 5 (results not shown), the three sets of 
mechanisms we consider-socioeconomic factors, housing characteristics, and environmental hazards - and all of their associated covariates account for approximately $29 \%$ and $59 \%$ of neighborhoods' racial disparities in lead toxicity among Black and Hispanic neighborhoods, respectively. ${ }^{12}$

Although socioeconomic composition and the physical housing environment are thus important to formulating a complete understanding of Chicago neighborhoods' toxic inequality by race, they do not tell the full story. Rather, lead toxicity appears to be its own environmental pathway through which racial segregation has contributed to the legacy of racial inequality in the United States. To demonstrate this point further, Figure 5 plots the relationships between neighborhoods' percentages of nonHispanic Black and Hispanic residents and predicted prevalence rates of elevated BLL based on Model 4 for years 1995 and 2010. All other continuous covariates are held at their means, and categorical covariates are held at their modes.

Figure 5 puts our finding of racial disparities in lead poisoning in stark relief-as the share of a neighborhood's Black population increases and Blacks become more spatially isolated, the prevalence rate of elevated BLL in children increases sharply as well, all else held constant. However, there is a clear period effect, and the relationship between residential segregation and lead toxicity is much weaker by 2010 than it was in 1995. A similar pattern is observed with respect to neighborhoods' Hispanic populations. When interpreting Figure 5, it is important to note that predicted prevalence rates for varying percentages of neighborhood Hispanic populations are calculated holding the neighborhood-level non-Hispanic Black population at its mean (41.5\%). Given the strong relationship between residential segregation among Blacks and children's prevalence rates of elevated BLL, as well as the fact that Blacks comprise a larger portion of Chicago's population and experience more segregation than Hispanics do,
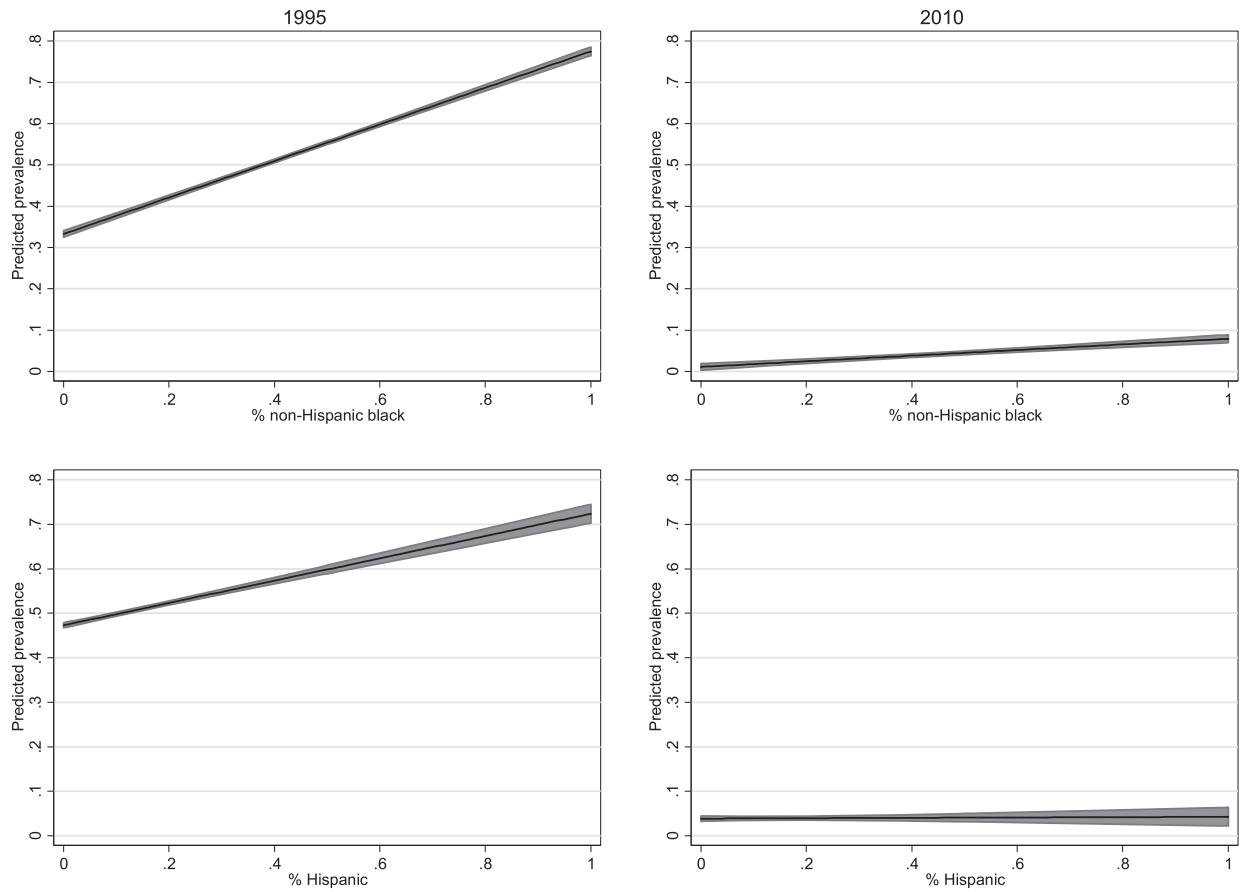

Fig. 5. Predicted Block-Group Prevalence Rates (95\% CI) of Elevated BLL ( $\geq 6 \mu \mathrm{g} / \mathrm{Dl}$ ) from Conditional Model 4 in Table 1, by Racial/Ethnic Composition and Year.

All Other Variables Held at Their Means (Continuous) or Modes (Categorical). 
the predicted prevalence rates with $0 \%$ Hispanics and $41.5 \%$ Blacks are higher than predicted prevalence rates with $0 \%$ Blacks and $17.2 \%$ Hispanics, the mean population of Hispanics at the neighborhood level.

\section{CONCLUSION}

If pictures could talk, Figures 3-5 would speak volumes about the racial and ethnic disparities in lead toxicity that children in segregated Chicago neighborhoods have had to endure, both historically and in the contemporary era-Flint, Michigan, is not an aberration. We have shown, for example, that Black and Hispanic neighborhoods exhibited extraordinarily high rates of lead toxicity compared to White neighborhoods at the start of our study in 1995, in some cases with prevalence rates topping $90 \%$ of the child population. Black disadvantage in particular is pronounced not only relative to Whites but even relative to Hispanics (Figure 4), in every year from 1995-2013. The profound heterogeneity in the racial ecology of what we call toxic inequality is partially attributable to socioeconomic factors, such as poverty and education, and to housing-related factors, such as unit age, vacancy, and dilapidation. But controlling these factors, neighborhood prevalence rates of elevated BLL remain closely linked to racial and ethnic segregation.

Our findings reflect a form of biosocial stratification (Massey 2004; Massey and Wagner, 2016) and an underappreciated kind of neighborhood effect (Sampson 2012) that reinforces racial inequality. Indeed, lead toxicity is a source of ecological inequity by race and a pathway through which racial inequality literally gets into the body. It might seem surprising that the structural mechanisms we consider-socioeconomic factors, housing characteristics, and environmental hazards-all of which are wellmeasured based on either census data or detailed observations, do not fully explain racial disparities in elevated BLL. But this general finding is in line with prior research at both the individual and ecological levels that shows direct links between racial segregation and both environmental hazards and poor health outcomes (e.g., Crowder and Downey, 2010; Downey 2006; Williams and Collins 2001). Consistent with this literature, we suspect that the remaining, unexplained racial disparities reflect the disadvantaged environmental aspects of racially-segregated neighborhoods that our measures do not capture.

Future research should thus incorporate additional measures of neighborhood environments to help further untangle the sources of racial disparities in lead toxicity. For example, landlord neglect of private housing conditions and institutional neglect of the indoor environments of daycare centers and schools may contribute to the link between racial segregation and health adversities like lead poisoning. Examining neighborhood reinvestment patterns and city infrastructure projects may also help to explain the persistence of racial disparities in lead exposure. During our study period, White neighborhoods in Chicago were much more likely to gentrify than minority neighborhoods (Hwang and Sampson, 2014). The differential cleanup of contaminated soil around formerly-toxic plants may be a hidden part of the story of gentrification.

Future research concerning lead toxicity at the individual level should also incorporate neighborhood-level and spatial theories of how inequality is created and maintained in order to fully understand the determinants of individual-level lead exposure as well as the relationships between individual-level lead exposure and later developmental and behavioral outcomes. Our research here was structural but with direct implications for individual-level exposure and life-course outcomes. More broadly, 
considering the toxicological landscape and its interaction with numerous forms of stratification can enhance our understandings of the individual-level mechanisms through which social inequalities are reproduced.

Finally, we wish to conclude on a positive note, pointing to the dramatic declines in lead toxicity across Chicago, especially in neighborhoods that began the period with very high prevalence rates. These declines reflect the success of public lead reduction efforts, including rigorous testing, lead-based paint abatement of homes and other locations where children spend considerable time, and improvements in nutritional status among children. A universal program, these efforts disproportionately benefited minority neighborhoods, where lead levels had been particularly toxic. In this sense, population health interventions may be seen as an important source of reducing racial inequalities. To be sure, Black-White disparities remain, but the absolute improvement in the lives of Black children is a source of good news. The medical community is to be commended for bringing the lead epidemic to the attention of the public and prodding us to include lead toxicity in our theoretical framework and policy understanding of how racial inequality is perpetuated, and in some cases, as here, markedly reduced.

Corresponding author: Robert J. Sampson, Department of Sociology, Harvard University, Cambridge, MA 02138. E-mail: rsampson@wjh.harvard.edu

\section{ACKNOWLEDGMENT}

This paper was supported in part by a grant from the Hymen Milgrom Supporting Organization. We thank Emile Jorgensen of the Chicago Department of Public Health for his assistance with the lead data and Chris Muller for comments.

\section{NOTES}

1. See also Bruce McEwen (1998) and Douglas Massey and Brandon Wagner (2016).

2. Using population counts from the 1990 and 2000 Decennial Censuses, we estimated CDPH's block group-level testing coverage to be between $30 \%$ and $50 \%$, with higher coverage in predominantly-Black and Hispanic neighborhoods relative to predominantly-White neighborhoods. Our results are robust to weighting the regression models by block grouplevel testing coverage and to the inclusion of testing coverage as an independent variable.

3. Because the videotape data required the expensive and time-consuming task of first viewing and then coding, a random sub-sample of 15,141 face blocks was selected for coding, an average of about thirty face blocks per block group. Coders were trained in multiple sessions. Additionally, new observers recoded a random $10 \%$ of all coded face blocks, and the results were compared. This test produced over $98 \%$ inter-coder agreement.

4. For further details see Robert Sampson and Stephen Raudenbush (2004, pp. 338-339).

5. We geocoded just over forty-five historical smelting plants in Chicago that were identified in a 2001 investigative study as unknown to the EPA (Eckel et al., 2001). For further details and maps see http://usatoday30.usatoday.com/news/nation/smeltinglead-contamination/\#testing/ (accessed June 15, 2016). We also geocoded and include another ten plants identified by William Eckel and colleagues (2001) that the EPA was already aware of. Our indicator includes sites at which smelting plants were shut down because lead persists in the soil and can be tracked into homes.

6. Overall, the average block group-level prevalence rates across all years for observations with and without missing data are both 0.19. Additionally, when the HLM models are run on the subset of observations with at least ten lead tests in each block group-year pair (36,117 observations from 2282 block groups), the results are very similar.

7. Given the segregated nature of housing in Chicago, Figure 3 appears virtually identical if we substitute majority ( $>50 \%$ ) racial group instead of the $70 \%$ cut-off that we show. 
8. Neighborhood poverty rates may be capturing multiple aspects of neighborhoods that are often highly correlated. When we add median household income to the model, its relationship with initial prevalence rates of elevated BLL is not statistically significant and the results presented in Model 2 remain virtually unchanged. However, the unemployment rate does account for part of the relationship between neighborhood poverty and prevalence rates of elevated BLL. And the percentage of individuals with less than a high school education fully accounts for the relationship between neighborhood poverty rate and prevalence rate of elevated BLL at baseline, given the other controls in Model 2.

9. When median housing value is added to the model, the results do not change, and its relationship with the neighborhood prevalence of elevated BLL is very small in magnitude.

10. This result holds if block groups' exposure to highway traffic is measured using a 0.2 mile buffer around Chicago's major highways instead of the 0.1 mile buffer we employ.

11. Similarly, the percentage of housing units with $\geq 5$ units in a structure and the percentages of units with $\geq 20$ units are also each significantly and negatively associated with initial prevalence rates of elevated BLL. However, including these indicators does not meaningfully alter the rest of our results.

12. We conducted three additional tests to assess the robustness of the major results in Table 1 . First, when the models in Table 1 are re-estimated using ordinary least square models with standard errors clustered at the block group level and weighted by the numbers of lead tests that comprise each observation, the results are very similar, particularly for the coefficients associated with racial ecology. Second, results are robust to centering time at 1996 or at 1997 instead of at 1995. Third, when the models in Table 1 are run for the baseline prevalence rate adjusting for spatial autocorrelation at the block group level, the results are, again, very similar, especially for the racial ecology indicators.

\section{REFERENCES}

Acevedo-Garcia, Dolores and Kimberly A. Lochner (2003). Residential Segregation and Health. In Ichiro Kawachi and Lisa Berkman (Eds.), Neighborboods and Health, pp. 265-281. New York: Oxford University Press.

Bellinger, David, Alan Leviton, Jone Sloman, Michael Rabinowitz, Herbert L. Needleman, and Christine Waternaux (1991). Low-Level Lead Exposure and Children's Cognitive Function in the Preschool Years. Pediatrics, 87(2): 219-227.

Canfield, Richard L., Charles R. Henderson, Jr., Deborah A. Cory-Slechta, Christopher Cox, Todd A. Jusko, and Bruce P. Lanphear (2003). Intellectual Impairment in Children with Blood Lead Concentrations Below $10 \mathrm{Mg}$ Per Deciliter. New England Fournal of Medicine, 348(16): 1517-1526.

Chiodo, Lisa M., Sandra W. Jacobson, and Joseph L. Jacobson (2004). Neurodevelopmental Effects of Postnatal Lead Exposure at Very Low Levels. Neurotoxicology and Teratology, 26(3): 359-371.

Crowder, Kyle and Liam Downey (2010). Interneighborhood Migration, Race, and Environmental Hazards: Modeling Microlevel Processes of Environmental Inequality. American fournal of Sociology, 115(4): 1110-1149.

Downey, Liam (2006). Environmental Racial Inequality in Detroit. Social Forces, 85(2): 771-796.

Drake, St. Clair and Horace R. Cayton (1945). Black Metropolis: A Study of Negro Life in a Northern City. Chicago, IL: University of Chicago Press.

Du Bois, W. E. B. (1899). The Philadelphia Negro: A Social Study. Philadelphia, PA: University of Pennsylvania Press.

Eckel, William P., Michael Rabinowitz, and Gregory Foster (2001). Discovering Unrecognized Lead-Smelthing Sites by Historical Methods. American fournal of Public Health, 91(4): 625-627.

Goodnough, Abby (2016). Flint Weighs Scope of Harm to Children Caused by Lead in Water. The New York Times, January 30, A1.

Hanchette, Carol L. (2008). The Political Ecology of Lead Poisoning in Eastern North Carolina. Health and Place, 14(2): 209-216.

Hwang, Jackelyn, and Robert J. Sampson (2014). Divergent Pathways of Gentrification: Racial Inequality and the Social Order of Renewal in Chicago Neighborhoods. American Sociological Review, 79(4): 726-751.

Jones, Robert L., David M. Homa, Pamela A. Meyer, Debra J. Brody, Kathleen L. Caldwell, James L. Pirkle, and Mary Jean Brown (2009). Trends in Blood Lead Levels and Blood Lead Testing among U.S. Children Aged 1 to 5 Years, 1988-2004. Pediatrics, 123(3): e376-e385. 
Kaplowitz, Stan A., Harry Perlstadt, and Lori A. Post (2010). Comparing Lead Poisoning Risk Assessment Methods: Census Block Group Characteristics vs. Zip Codes as Predictors. Public Health Reports, 125(2): 234-245.

Krieger, Nancy (2014). Discrimination and Health Inequities. In Lisa F. Berkman, Ichiro Kawachi, and Maria Glymour (Eds.), Social Epidemiology, pp. 63-125. New York: Oxford University Press.

Krieger, Nancy, J. T. Chen, P. D. Waterman, M. J. Soobader, S. V. Subramanian, and R. Carson (2003a). Choosing Area Based Socioeconomic Measures to Monitor Social Inequalities in Low Birth Weight and Childhood Lead Poisoning: The Public Health Disparities Geocoding Project (U.S.). Fournal of Epidemiology and Community Health, 57(3): 186-199.

Krieger, Nancy, J. T. Chen, P. D. Waterman, D. H. Rehkopf, and S. V. Subramanina (2003b). Race/Ethnicity, Gender, and Monitoring Socioeconomic Gradients in Health: A Comparison of Area-Based Socioeconomic Measures: The Public Health Disparities Geocoding Project. American Fournal of Public Health, 93(10): 1655-1671.

Lanphear, Bruce P., Robert S. Byrd, Peggy Auinger, and Stanley J. Schaffer (1998). Community Characteristics Associated with Elevated Blood Lead Levels in Children. Pediatrics, 101(2): 264-271.

Lanphear, Bruce P., Richard Hornung, Jane Khoury, Kimberly Yolton, Peter Baghurst, David C. Bellinger, Richard L. Canfield, Kim N. Dietrich, Robert Bornschein, Tom Greene, Stephen J. Rothenberg, Herbert L. Needleman, Lourdes Schnaas, Gail Wasserman, Joseph Graziano, and Russell Roberts (2005). Low-Level Environmental Lead Exposure and Children's Intellectual Function: An International Pooled Analysis. Environmental Health Perspectives, 113(7): 894-899.

Lanphear, Bruce P., Michael Weitznan, and Shirley Eberly (1996). Racial Differences in Urban Children's Environmental Exposures to Lead. American Fournal of Public Health, 86(10): 1460-1463.

Massey, Douglas S. (2004). Segregation and Stratification: A Biosocial Perspective. Du Bois Review: Social Science Research on Race, 1(1): 7-25.

Massey, Douglas S. and Nancy Denton (1993). American Apartheid: Segregation and the Making of the Underclass. Cambridge, MA: Harvard University Press.

Massey, Douglas S. and Mitchell L. Eggers (1990). The Ecology of Inequality: Minorities and the Concentration of Poverty, 1970-1980. American fournal of Sociology, 95(5): 1153-1188.

Massey, Douglas and Brandon Wagner (2016). Segregation, Stigma, and Stratification: A Biosocial Model. In Brenda Major, John Dovidio, and Bruce Link (Eds.), The Oxford Handbook of Stigma, Discrimination, and Health. New York: Oxford University Press, forthcoming.

McEwen, Bruce S. (1998). Stress, Adaptation, and Disease: Allostasis and Allostatic Load. Annals of the New York Academy of Sciences, 840(1): 33-44.

National Research Council (1993). Measuring Lead Exposure in Infants, Children and Other Sensitive Populations. Washington, DC: National Academy of Sciences.

Needleman, Herbert L. and D. Bellinger (1991). The Health Effects of Low Level Exposure to Lead. Annual Review of Public Health, 12: 111-140.

Needleman, Herbert L., Charles Gunnoe, Alan Leviton, Robert Reed, Henry Peresie, Cornelius Maher, and Peter Barrett (1979). Deficits in Psychologic and Classroom Performance of Children with Elevated Dentine Lead Levels. New England Journal of Medicine, 300(13): 689-695.

Needleman, Herbert L., Julie A. Riess, Michael J. Tobin, Grechen E. Biesecker, and Joel B. Greenhouse (1996). Bone Lead Levels and Delinquent Behavior. Fournal of the American Medical Association, 275(5): 363-369.

Oyana, Tonny J. and Florence M. Margai (2010). Spatial Patterns and Health Disparities in Pediatric Lead Exposure in Chicago: Characteristics and Profiles of High-Risk Neighborhoods. The Professional Geographer, 62(1): 46-65.

Perkins, Kristin L. and Robert J. Sampson (2015). Compounded Deprivation in the Transition to Adulthood: The Intersection of Racial and Economic Inequality among Chicagoans, 1995-2013. RSF: The Russell Sage Foundation Fournal of the Social Sciences, 1(1): 35-54.

Pirkle, J. L., R. B. Kaufmann, D. J. Brody, T. Hickman, E. W. Gunter, and D. C. Paschal (1998). Exposure of the U.S. Population to Lead, 1991-1994. Environmental Health Perspectives, 106(11): 745-750.

Rogan, Walter J. and James H. Ware (2003). Exposure to Lead in Children: How Low Is Low Enough? The New England fournal of Medicine, 348: 1515-1516.

Sampson, Robert J. (2012). Great American City: Chicago and the Enduring Neighborhood Effect. Chicago, IL: University of Chicago Press. 
Sampson, Robert J. and Stephen W. Raudenbush (2004). Seeing Disorder: Neighborhood Stigma and the Social Construction of Broken Windows. Social Psychology Quarterly, 67(4): 319-342.

Sharkey, Patrick T. (2013). Stuck in Place: Urban Neighborboods and the End of Progress toward Racial Equality. Chicago, IL: University of Chicago Press.

Sharkey, Patrick T. and Robert J. Sampson (2015). Violence, Cognition, and Neighborhood Inequality in America. In Russell K. Schutt, Larry J. Seidman, and Matcheri S. Keshavan (Eds.), Social Neuroscience: Brain, Mind, and Society, pp. 320-339. Cambridge, MA: Harvard University Press.

Stretesky, Paul B. (2003). The Distribution of Air Lead Levels across U.S. Counties: Implications for the Production of Racial Inequality. Sociological Spectrum, 23(1): 91-118.

Williams, David R. and Chiquita Collins (2001). Racial Segregation: A Fundamental Cause of Racial Disparaties in Health. Public Health Reports, 116(5): 404-416.

Wilson, William Julius ([1987] 2012). The Truly Disadvantaged: The Inner City, the Underclass, and Public Policy. Chicago, IL: University of Chicago Press. 